\title{
The Determinant Parameters of Knowledge Transfer among Academicians in Colleges of Chennai Region
}

\author{
P. Mary Jeyanthi, Santosh Kumar Shrivastava \\ Business Analytics, Institute of Management Technology, Nagpur, India \\ Email:pmjeyanthi@imtnag.ac.in, sshrivastava@imtnag.ac.in
}

How to cite this paper: Jeyanthi, P.M. and Shrivastava, S.K. (2019) The Determinant Parameters of Knowledge Transfer among Academicians in Colleges of Chennai Region. Theoretical Economics Letters, 9, 752760.

https://doi.org/10.4236/tel.2019.94049

Received: February 11, 2019

Accepted: April 1, 2019

Published: April 4, 2019

Copyright () 2019 by author(s) and Scientific Research Publishing Inc. This work is licensed under the Creative Commons Attribution International License (CC BY 4.0).

http://creativecommons.org/licenses/by/4.0/

\section{cc) (†) Open Access}

\begin{abstract}
Purpose of the Study: The term "Knowledge" is measured as the most significant asset in every educational Institution and managing the knowledge is considered tough to succeed in the Educational Institution status. If the professors or lecturers have to use the best insights of knowledge sharing, then they have to learn how the knowledge is gathered, transferred and used in the Educational Institution. Data/Methodology: The intention of this study is to represent the conditions in which the development of new knowledge arises across the academic organizational borders and the factors that influence this process. Primary data are collected for this study. 18 questions are designed to ascertain the views of the academic faculties on the significance of knowledge transfer, strategies to encourage knowledge transfer, strategies to identify the barriers in knowledge sharing. The t-test is engaged to find the need for knowledge sharing is better communicated in engineering Colleges or in arts \& science colleges. Findings: The respondent's view was also examined to reveal the most agree as for the determining factors of knowledge sharing and its barriers. This result also provides the respondents feel that there is a scarcity of knowledge sharing approaches, a lack of knowledge archives, and also an inadequacy of awareness of the benefit of KS in their organizations. Originality: The key objective of the paper is to scrutinize the determinant factors of knowledge sharing amid academic faculties working in engineering and Arts \& Science Colleges situated in the Chennai zone.
\end{abstract}

\section{Keywords}

Knowledge Sharing (KS), Academician, Knowledge Management (KM), Knowledge Transfer, KS Barriers 


\section{Introduction}

In our present economy, new emerging factors play a determinant role in the business environment. In developing countries, cost is not only the key parameter of the business environment nowadays, but also it should base on the development and production of Knowledge-based services and products. At present scenarios, knowledge has primarily measured a factor of production, laterally with labor, land, and capital. Knowledge will become the main key factor of the new economy as the world focuses on the "knowledge-based economy" [1]. The economic success in the future is going to be fully depended on how organizations or companies obtain, utilize and influence knowledge efficiently and effectively.

However, understanding the concept of knowledge has become a dilemma due to the lack of theories on the subject. This is primarily because of its intangible nature as it makes very tough to understand the concept of tacit knowledge. Likewise, companies or organizations may find it hard to handle knowledge effectively. Hence, a lot of investigation has to undertake in this domain so that a framework can be created to guide or support future research works. Generally, the significant area of knowledge management filed requires more attention in knowledge sharing [2]. Knowledge sharing is rooted within the knowledgeprocessing scope where knowledge is produced and effective knowledge management procedures must accentuate the knowledge sharing role to increase the topnotch outcome for the organizations.

\section{Objective}

Knowledge is seen as an important input in educational institutions since it allows the development and creation of competitive advantage. Organizations that can exploit the use of knowledge effectively can remain competitive. Effective knowledge management strategies can enhance efficiency, productivity and ultimately achieve long-term corporate goals. However, more importance is given on the knowledge enablers, so-called tangible features in studies about knowledge management. Currently, most knowledge-based organizations may have knowledge management strategies that are too general. Knowledge management procedures must be broken down into precise procedures such as knowledge sharing procedures. Knowledge management is the key parameters to increase individual performance and also organizations. This paper will help the readers to understand the importance of Knowledge management and Knowledge sharing parameters and to implement the same.

The unique of this paper is to trained services organization, revealed that the "knowledge is power" mentality between the Faculties were a key obstacle hindering effective KS. Academicians were found to oppose the knowledge sharing because of lack of time and fear of losing importance within the organization and many real-time implications. This study examines the Art \& Science Colleges and Engineering Colleges; since there are vast different parameters from these two educational sectors such as working culture, code of conduct, Knowledge Receiving \& Knowledge Donating. 


\section{Literature Review}

Zhang, X. and Jiang, J. Y. [1] in their study examined knowledge-sharing phenomena from the perspective of recipients' characteristics. Particularly, this study tests the impact of knowledge receivers' expertise, personal relationship and learning attitude through knowledge sharer on knowledge sharers' readiness to share. And the outcome says that recipients' characteristics play various roles in many situations (proactive and responsive knowledge sharing) in stimulating the knowledge sharers' inducement to share. In responsive knowledge transfer, a learning attitude of the recipient and individual relationship with the knowledge sharer influences the sharer's readiness to share. In proactive knowledge transfer, professional skill and an individual relationship of the receiver with the sharer considerably influence the sharer's readiness to share.

Al-Busaidi, K.A., Olfman, L. [3] in their research focus on Inter-organizational knowledge sharing systems. (IOKSS) is crucial for scientific, economic and social improvement, particularly in knowledge-intense sectors. Knowledge sharing systems and processes refused only is conflicting with organizational and individual aspects, but also by technical, political and social inter-organizational facet [3]. This paper meant for investigating the knowledge worker impacts, IOKSS, peer, sector factors and organization of knowledge workers' target to transfer knowledge through IOKSS. Knowledge workers are the key shareholders that allow the IOKSS survival, and this study establishes that the human elements have an important direct effect on the aim to transfer knowledge through IOKSS. Further reasons, such as the IOKSS system, the organization and division factors showed indirect effects on knowledge workers' intention to transfer knowledge through IOKSS.

Chin; Yee \& Geok [4] in their study tried to investigate the knowledge-sharing barriers and strategies of academic faculties in Malaysia public and private universities which have acquired relatively small research consideration to date, and The general conclusion shows that private universities are more efficient and are more enthusiastic to transfer knowledge. Linking knowledge transfer with fair performance appraisals and nonmonetary rewards is robustly suggested in private universities, while recognition, monetary rewards, publication of knowledge on newsletters and websites and the use of suitable expertise tools and systems are powerfully suggested in public universities.

Roger Fullwood, Jennifer Rowley, Rachel Delbridge [5] showed in their study the limited previous research on knowledge sharing in universities, by prevailing the attitudes of and intentions towards knowledge transfer of UK studies, and by analyzing their views of some of the reasons that might be likely to effect on knowledge transfer activities, Respondents had optimistic attitudes towards knowledge sharing and their intents in this extent were also worthy. This may be related to their belief that knowledge sharing will improve and extend their relationships with colleagues, also offer opportunities for internal promotion and external appointments. Respondents are comparatively neutral concerning the 
approach in which they're led, and the function of the information technology (IT) and organizational structure in knowledge transfer. They have a comparatively stumpy level of affiliation to their university, lofty level of autonomy insights, attached to a great level of affiliation with their regulation.

The obstacles that reduce knowledge sharing can be categorized into the barriers at the organizational level and at the individual level. One of the key barriers that have been outlined frequently in the literature on knowledge management is culture [6]. Knowledge sharing was not successful in educational institutions as they are likely to alter their organizations' customs to adopt KS plans and practices. Organizations should come up with KS strategies that fit the existing organization's culture [7]. KS is also viewed alone as a special activity and not a division of the organization's goals. At the individual stage, it was observed that barriers to KS consist of the following, deficiency in communication skills and social networks, variations in culture, lack of time and lack trust [8].

Pauline and Mason [9] have done an empirical study in New Zealand on obstacles of Knowledge Management (KM) shows that the barriers are mainly inside the firms. Organizational culture, leadership, and management practices and lack of awareness and vision about KM were the main barriers inhibiting KM implementation.

\section{Methodology}

\subsection{Data Collection \& Analysis}

Two types of colleges have been considered for this study. First one is an Engineering college and another is an Arts and Science College from the Chennai region. 250 out of 300 academic faculties were selected from both the engineering colleges and arts \& Science College in Chennai. This was using a simple random sampling technique. Total Questionnaires for Analysis is 250; Out of which, 204 questionnaires were getting replies from the targeted population, from this, 4 questionnaires were considered not appropriate for the analysis. Finally, 200 questionnaires were considered for analysis.

\subsection{Instrument for Primary Data Collection}

1) To gather data for the A questionnaire analysis was adopted to gather the primary data in this review, the questionnaire comprises of two sections, and the first section covers the demographic information (Gender, Age, Designation Marital Status, and Type of Institution).

2) The second section comprises of 18 questions designed to ascertain the views of the academic faculties on the significance of knowledge transfer, strategies to encourage knowledge transfer, strategies to identify the barriers in knowledge sharing.

3) These were developed by the researcher relied on the theoretical background and literature review were appraised using a Likert-type scale which includes five points (ranging from 1 strongly oppose to 5 strongly have the same 
opinion) [10].

Respondent's profile and background information. The demographic and background variables used in this analysis are gender, age, status, designation and type of institution as per the data collected from Arts \& Science and Engineering college academicians (Table 1 ).

Based on the demographics data analysis and other profile information obtained, a majority of the respondents were female $(60 \%)$. The respondents are mostly from the age of 31 to 40 years (40\%), married (73.5\%), and are secure with a Lecturer/Senior Lecturer's position (64.5\%). 50\% of the participators are presently working for engineering college.

\subsection{Importance of Knowledge Sharing}

One of the aims of the research was to establish the degree to which KS was considered significant by the Respondents. This survey states that $59.5 \%$ of the respondents stating "strongly agree" and $37.5 \%$ stating "agree" to the statement. No respondents strongly disagreeing or disagree with the statement. As per the Questionaries' are collected from the Arts \& Science and Engineering college academicians, the outcomes of the survey are mentioned in Table 2.

Table 1. Respondents' demographic profile.

\begin{tabular}{cccc}
\hline Respondents' Profile & Classification & Frequency & Percentage \\
\hline Gender & Male & 80 & 40 \\
& Female & 120 & 60 \\
Age & $21-30$ & 40 & 20 \\
& $31-40$ & 80 & 40 \\
Status & $41-50$ & 45 & 22.5 \\
& Above 50 & 35 & 17.5 \\
& Married & 147 & 73.5 \\
& Unmarried & 53 & 26.5 \\
Type of Institution & Asst. Lecturer & 31 & 15.5 \\
& Lecturer & 129 & 64.5 \\
Designation & Associate. Professor & 28 & 14
\end{tabular}

Table 2. The significance of KS for the success \& growth of an educational institution.

\begin{tabular}{ccc}
\hline & Frequency & Percentage \\
\hline Strongly Agree & 119 & 59.5 \\
Agree & 77 & 37.5 \\
Neutral & 4 & 2 \\
Total & 200 & 100.00 \\
\hline
\end{tabular}


Respondents were furthermore asked to reply, whether the importance of KS is clearly communicated in their university/college. Around $63 \%$ of respondents said that they "agree" or "strongly agree" with the statement, as compared to $15.5 \%$ who "disagree" or "strongly disagree". A lot of respondents, $21.5 \%$ were in doubt. Results are provided in Table 3. This table data analysis is purely done by the feedback from the Chennai region, Arts \& Science and Engineering college academicians.

The t-test is engaged to find the need for knowledge sharing is better communicated in engineering Colleges or in arts \& science colleges. The requirement for sharing knowledge was much better communicated in art colleges than engineering colleges. The performance of $\mathrm{t}$-test is found in Table 4 .

The $\mathrm{t}$-test for comparing two sample means is given by following

$$
t=\frac{\overline{x_{1}}-\overline{x_{2}}}{\sqrt{\frac{s_{1}^{2}}{n_{2}}-\frac{s_{2}^{2}}{n_{2}}}}
$$

As per the data collected from Arts \& Science and Engineering colleges, to find the significant difference with $\mathrm{T}$-Test and to understand the requirement for Knowledge management.

\subsection{Views on Knowledge Receiving and Knowledge Donating}

Respondents were inquired to indicate the degree to which they were willing to share the knowledge and also the degree to which their colleagues were ready to distribute the knowledge. In Table 5, the first two statements relate to knowledge, donating and the last two statements relate to knowledge receiving. It can be observed that the self-motivated biases are apparent from the views expressed by the respondents. They have given a better rating when it comes to their

Table 3. Is the significance of Knowledge Transfer clearly communicated?

\begin{tabular}{ccc}
\hline & Frequency & Percentage \\
\hline Strongly Agree & 41 & 20.5 \\
Agree & 85 & 42.5 \\
Neutral & 43 & 21.5 \\
Disagree & 27 & 13.5 \\
Strongly Disagree & 4 & 2 \\
Total & 200 & 100 \\
\hline
\end{tabular}

Table 4. T-test for a significant difference between arts \& science and engineering colleges.

\begin{tabular}{cccccc}
\hline & College Type & $\mathrm{N}$ & Mean & Std. Deviation & Std. Error Mean \\
T-Test & Arts \& Science & 100 & 1.6000 & 0.75210 & 0.07521 \\
& Engineering & 100 & 1.4200 & 0.49604 & 0.04960 \\
\hline
\end{tabular}


Table 5. Views on knowledge receiving and knowledge donating.

\begin{tabular}{lccccc}
\hline \multicolumn{1}{c}{ Survey Questionnaires } & SA & A & N & D & SD \\
\hline $\begin{array}{l}\text { I am willing to share information } \\
\text { with my colleagues }\end{array}$ & $79(39.5)$ & $103(51.5)$ & $12(6)$ & $4(2)$ & 0 \\
$\begin{array}{l}\text { I am willing to share my lecture notes, } \\
\begin{array}{l}\text { Powerpoint slides and other } \\
\text { resources with my colleagues. }\end{array}\end{array}$ & $86(43)$ & $92(46)$ & $17(8.5)$ & $5(2.5)$ & 0 \\
$\begin{array}{l}\text { My colleagues are willing to } \\
\text { share information with me. }\end{array}$ & $44(22)$ & $82(41)$ & $37(18.5)$ & $30(15)$ & $7(3.5)$ \\
$\begin{array}{l}\text { My colleagues are willing to share } \\
\text { their notes, powerpoint slides, } \\
\text { and other resources with me. }\end{array}$ & $40(20)$ & $75(37.5)$ & $38(19)$ & $25(12.5)$ & $22(11)$ \\
\hline
\end{tabular}

readiness to share knowledge and a lower rating to when it comes to sharing of knowledge with their colleagues.

On a Likert's five-point scale value of 1 was assigned to "strongly agree"; as such, a low mean score represents the high intensity of that variable in terms of barriers. The barriers have been set in order of the mean value from small to big value. It can be seen that lack of rewards and recognition, lack of time, and lack of informal and formal activities to cultivate knowledge sharing, have been identified as the strongest barriers, and while poor communication skills of the faculties and lack of IT systems were rated low in terms of barriers to KS.

Refer the Table 6, very strong case was observed for KS through regular emphasis by the top management of the Colleges. This means that people would be more willing to share their knowledge if they felt that the top management wants it. It can also be observed from this table that there is a strong case for linking KS with rewards and performance appraisal. Besides, respondents experience a great need for the Colleges to motivate academicians to transfer knowledge on its internet site and make use of newsletters to spread the knowledge. This result also provides the respondents feel that there is a scarcity of knowledge sharing approaches, a lack of knowledge archives, and also an inadequacy of awareness of the benefit of KS in their organizations.

\section{Conclusions}

Academic Institutions were considered as the huge repository of knowledge. Academic Institutions like any organization which is paying much attention to knowledge, are increasing the efforts in enhancing their quality of education performance. Doing so requires the availability of adequate knowledge, where the academic faculties play a major role in helping the colleges to acquire adequate knowledge. Based on this research, KS should be continuously promoted and barriers should be limited. The strategies for promoting knowledge sharing may be specific. Assistance from the top management in cheering academicians to publish and distribute the knowledge through several available methods is highly suggested. More awareness must be created to ensure that 
Table 6. Methods to improvise knowledge sharing.

\begin{tabular}{|c|c|c|}
\hline Promotion of Knowledge Sharing & $\begin{array}{l}\text { Mean } \\
\text { Scores }\end{array}$ & $\begin{array}{l}\% \text { of "SA" } \\
\text { and "A" }\end{array}$ \\
\hline $\begin{array}{l}\text { Knowledge sharing can become a culture in the organization } \\
\text { if top management often displays and strength the theme that } \\
\text { "knowledge is the lifeblood of an organization' }\end{array}$ & 1.50 & 87.3 \\
\hline Technology plays an essential role in encouraging Knowledge Sharing & 1.516 & 86.4 \\
\hline $\begin{array}{l}\text { The University/College should encourage the faculties to publish } \\
\text { their knowledge on the university/college website or pool it } \\
\text { in the library from where others could access it. }\end{array}$ & 1.515 & 84.5 \\
\hline $\begin{array}{l}\text { The university/college must use its circular or other similar tools to } \\
\text { spread knowledge and encourage knowledge sharing among the faculty }\end{array}$ & 1.504 & 81.6 \\
\hline $\begin{array}{l}\text { Knowledge sharing can be encouraged if it is linked to the } \\
\text { performance assessment of the faculty. }\end{array}$ & 1.50 & 79.6 \\
\hline Knowledge sharing could be encouraged if it is clearly linked to rewards. & 1.473 & 76.0 \\
\hline $\begin{array}{l}\text { Nonfinancial rewards (appreciation, recognition) shall be more } \\
\text { efficient in encouraging knowledge sharing than financial rewards. }\end{array}$ & 1.498 & 69.7 \\
\hline $\begin{array}{l}\text { Knowledge sharing can be encouraged if there is a designated } \\
\text { knowledge officer at the university/college. }\end{array}$ & 1.504 & 61.7 \\
\hline $\begin{array}{l}\text { There is raising awareness of the gain of knowledge } \\
\text { sharing in my organization. }\end{array}$ & 1.503 & 57.7 \\
\hline There exists a knowledge database in my organization. & 1.477 & 51.6 \\
\hline There occurs a knowledge sharing plan for my organization. & 1.625 & 46.1 \\
\hline
\end{tabular}

people understand the benefits of knowledge sharing. A decent knowledge flow in working groups and collaborative societies of faculty members within a department or through different university departments would lead to better research and education management.

Previous studies regarding Knowledge Management across institutions as a common whole. Instead, Arts \& Science and Engineering colleges are completely different in the perspective of organizational structure, Code of conduct and knowledge management too. In this paper, we analyzed the various factors of Knowledge sharing and Knowledge Creation. It takes a comprehensive view on knowledge and argues that defining knowledge management through Arts \& Science and Engineering Colleges are different. The conversion between information and knowledge is best accomplished through social and Economic actors. The roots of this view can be implemented in theoretical and technological subsystems; that is one of the reasons we believe that knowledge management is best and it's carried out through the knowledge optimization in the perspective of the organization.

\section{Conflicts of Interest}

The authors declare no conflicts of interest regarding the publication of this paper. 


\section{References}

[1] Zhang, X. and Jiang, J.Y. (2015) With Whom Shall I Share My Knowledge? A Recipient Perspective of Knowledge Sharing. Journal of Knowledge Management, 19, 277-295. https://doi.org/10.1108/JKM-05-2014-0184

[2] Alhawary, F.A., Abu-Rumman, A.H. and Alshamaileh, M.O. (2017) Determinant Factors of Knowledge Sharing among Academic Staff in the Jordanian Universities. European Journal of Social Sciences, 55, 415-426.

[3] Al-Busaidi, K.A. and Olfman, L. (2017) Knowledge Sharing through Inter-Organizational Knowledge Sharing Systems. VINE Journal of Information and Knowledge Management Systems, 47, 110-136. https://doi.org/10.1108/VJIKMS-05-2016-0019

[4] Chin, W.C., Yee, Y.Y. and Geok, C.G. (2014) Knowledge Sharing of Academic Staff. Library Review, 63, 203-223. https://doi.org/10.1108/LR-08-2013-0109

[5] Fullwood, R., Rowley, J. and Delbridge, R. (2013) Knowledge Sharing amongst Academics in UK Universities. Journal of Knowledge Management, 17, 123-136. https://doi.org/10.1108/13673271311300831

[6] Paulin, D. and Suneson, K. (2012) Knowledge Transfer, Knowledge Sharing and Knowledge Barriers. EJKM, 10, 321.

[7] Sharratt, M. and Usoro, A. (2003) Understanding Knowledge-Sharing in Online Communities of Practice. Electronic Journal of Knowledge Management, 1, 187-196.

[8] Cheng, M.Y., Ho, J.S.Y. and Lau, P.M. (2009) Knowledge Sharing in Academic Institutions: A Study of Multimedia University Malaysia. Electronic Journal of Knowledge Management, 7.

[9] Pauline, D. and Mason, D. (2002) 2002 New Zealand Knowledge Management Survey: Barriers and Drivers.

[10] Rahman, M.S., Osmangani, A.M., Daud, N.M. and AbdelFattah, F.A.M. (2016) Knowledge Sharing Behaviors among Non Academic Staff of Higher Learning Institutions: Attitude, Subjective Norms and Behavioral Intention Embedded Model. Library Review, 65, 65-83. https://doi.org/10.1108/LR-02-2015-0017 